\title{
Training for Community Psychiatry
}

\author{
Hugh Freeman, Consultant Psychiatrist, Hope Hospital, Salford, Manchester
}

In 1968 the Royal Commission on Medical Education recommended that 'every psychiatrist should be familiar with the conduct of community psychiatry'. This seems an uncontroversial piece of advice, but what is 'the conduct of community psychiatry'? At the time of the Royal Commission, there was certainly no special training at all in anything that could reasonably have been regarded as such.

The Richmond Fellowship report ${ }^{1}$ emphasized that community care should be a positive policy, and not merely a shift away from large mental hospitals. Patients should be helped to achieve their own personal goals as far as possible, the effects of disease or distress be prevented or ameliorated, and a service based on the principles of district responsibility, comprehensive provision, and continuity of care should be established. The fragmentation of effort which is inherent in the separate development of different services, and the barriers existing between different professions, could be overcome by multidisciplinary teamwork and by partly shared training. This helps to give a more clearly defined idea of what the objectives of community psychiatric training ought to be, but the problem remains of how to achieve it.

It is only quite recently that specialist training in psychiatry moved out of the apprenticeship era, so that perhaps we should not expect too much too quickly. A landmark in this process was the report by Dr Peter Brook in 1974 of his investigation into psychiatric manpower and postgraduate education. ${ }^{2}$ When trainees were then asked about their career intentions, 27 per cent said they would like this to be mostly in a community setting and 20 per cent said definitely not in that setting. It was therefore much less popular than a general hospital unit, a teaching hospital, or even a mental hospital. Foreign graduates showed a relatively low degree of interest in community work, which was disappointing, in view of the fact that this would seem to be an appropriate pattern for developing countries.

However, these figures need to be qualified by the fact that there was much ignorance among trainees about the potentialities of community work, and the report recommended that they should have more practical experience of this kind, as well as better career guidance and counselling. When senior trainees were asked whether they felt they were getting adequate experience of psychiatry in community settings, two-thirds said that they were not; this referred to activities such as domiciliary visits, visiting old people's homes, and visiting hostels. Asked about the adequacy of supervision in community work, two-thirds of registrars and senior registrars considered this was inadequate, and almost as many of the recently appointed consultants felt the same about their training. Enquiry about the amount of contact

This paper was given to the Social and Community Psychiatry Section of the College in February 1983. between trainees and social workers or with health workers outside the hospital showed that this was generally very limited, but depended mainly on the organization or attitude of individual hospitals.

Brook's subsequent reports, of 1980 and $1981,{ }^{3}$ based on enquiries to recently appointed consultants, showed modest degrees of improvement in this situation, but in $1981 \mathrm{com}$ munity work was still one of the aspects for which there was least satisfaction, only 38 per cent considering that training in it was adequate in quantity and adequately supervised. The survey figures for consultants appointed in 1978-81 showed virtually no change in this respect; whereas only 32 per cent of those appointed from teaching hospitals were satisfied about their training in community work, 46 per cent of those appointed from non-teaching hospitals were satisfied. The actual numbers in each category of appointee were about equal. If one can draw a conclusion from this, it is that teaching hospitals particularly should pay relatively more attention to the community aspects of training.

When I asked what were the feelings of trainees in general on this question, the Collegiate Trainees' Committee replied that they regarded training in community psychiatry as largely non-existent, and that though some posts purport to offer training of this kind, with a few exceptions, in fact they do not. They concluded: 'In this sorry state of affairs, any development in training which increased the available experience would be welcome.'

In this discussion, it would obviously be wrong to neglect the special position of the Maudsley Hospital. There, each entry group of about ten trainees normally passes through four teaching blocks, lasting six months each, and one of these is described as social psychiatry. However, a block may be missed if a trainee has had previous experience in it. The clinical part of the 'social block' is spent on one of the five units participating in the catchment area service; three of these units are in the District Services Centre. However, the extramural aspects of this clinical experience are uncertain; there is no community nursing service and domiciliary visiting by trainees seems to be fairly rare. In a survey by $\mathrm{Dr} \mathrm{S}$. Kumar of trainees' views of the Maudsley training, it appeared that they generally showed less interest in social and community teaching than in the other blocks, and saw the subject as being too amorphous. This situation at the centre of postgraduate psychiatric teaching in this country is disquieting, and suggests that things have not greatly improved since the old days when phenomenology was all.

In the rest of the country progress has not always been in a forward direction. In Cambridge, whereas a registrar used to spend six months working in the day hospitals and going on visits to community clinics in the Fens, this special experience has been discarded from the rotational training scheme. The other posts which do offer special experience are mentioned in the report of the Working Party on 
specialist status which met under my chairmanship, and reported in 1982.4 It looked at this question because of concern about deficiencies both in the service and training aspects of community psychiatry.

A special Bradford registrar post was reported to work best when spent entirely in the two day hospitals, together with general hospital liaison work, domiciliary visits, and contact with social services and primary health care, etc. The teaching programme includes a weekly group leaders' group for those staff who run such sessions regularly, and a multidisciplinary working party of both hospital and community staff, which meets periodically to discuss issues relating to the service.

At Lewisham there is a supernumerary registrar attached to the Crisis Intervention Team at the Mental Health Advice Centre, but this post is outside the rotational training scheme. The special experience here comes from close working relationships with primary care personnel, together with staff from other disciplines, and from the opportunity to assess and treat patients in their homes.

At Tameside in Greater Manchester there is a one-year slot for a senior registrar, as part of the rotation based in the Professional Department; this period is spent at Brindle House mental health centre, which has a number of interesting and unusual features about its work.

At Dingleton in the Scottish Borders, which is outside any rotational scheme, GP trainees seem to fit particularly well into the philosophy practised there, which may be more acceptable to doctors preparing to work in the community than to those who will be based in hospitals. Also, it does not have the emphasis on treatment of severe neurosis which characterizes most psychotherapy training, but is more broadly based.

Claybury Hospital has established a community mental health centre in Leytonstone, where both a senior registrar and an SHO spend part of their time. Trainees there are said to go out regularly on domiciliary visits, and the senior registrar at present undertakes clinics in social services offices.

The Tavistock Clinic holds seminars for primary caregivers, and provides a consultative service to many outside agencies. The trainees employed at the Clinic obviously learn its special skills, but apart from courses on consultative work in community mental health, it does not seem to contribute much to the training of psychiatrists elsewhere-which would perhaps be a valuable service.

The well-known Napsbury crisis intervention service involves those trainees who are attached to the consultants in it, but not the others. Where an unusual and a conventional service are operating side by side, in this way, it seems quite likely that there could be particular problems for trainees. These unconventional services may make heavy personal demands on trainee doctors, which may not always be justified.

Finally, there is the unique post in Craigmillar, Edinburgh, which is essentially one alongside the conventional service, rather than replacing it; it raises fundamental questions of where the boundaries of psychiatric practice are to be drawn, and to what extent neurotic, psychosomatic, personality and psychosocial problems are rather the reponsibility of GPs, or of social workers, community nurses, health visitors and volunteers.

Two contrary views can be taken about these questions, both legitimate in their way. On the one hand, as Dally ${ }^{5}$ has pointed out, it may be leading trainees up the garden path to suggest that they will be intervening widely in society, and thereby curing it of its chronic problems, while as far as the huge mass of minor morbidity in the population is concerned, they may achieve no more with this as psychiatrists than does good primary care. Psychiatrists must know 'what they are trying to achieve and why'.

On the other hand, much present-day specialist training has been described as little more than learning to make diagnoses and prescribe drugs, whereas psychiatric skills ought to include knowledge of why people feel as they do, and helping them to understand themselves and others. The persisting problem of recruitment in psychiatry may be at least partly due to the fact that those doctors who are interested in working outside hospitals and with the 'whole person', are not attracted enough by it, in its present form.

I see the merits of both these views and hope that they can both be accommodated. In the case of my own trainees, I am constantly aware that they should have more extramural experience, yet hesitate to add further commitments to a heavy load of work within the hospital, together with study and research.

From his extensive knowledge of present conditions through the Health Advisory Service, Dr Donald Dick told me that formal community psychiatry training posts are almost non-existent. However, a substantial majority of services are now related to catchment areas, and trainees are regarded as part of the sector team. The problem is that they see themselves primarily as managing a flow of patients, referred from the community, and returned to it with gradually reducing hospital attention. The training question may hinge primarily on a shift in attitudes, from dealing with presented pathology, to the containment and eventual reduction of psychiatric morbidity in the catchment population. This involves not only providing the special skills of psychiatry, but supporting and working with primary care, social services and other related organizations.

To achieve this, Dr Dick suggests that the training of psychiatrists should take place with GPs, community physicians, and social workers, while in return, psychiatry made room for these people within its own training schemes, in areas of mutual interest. It should also have a much better relationship with community medicine, e.g. in receiving information about the community's health. The present training of community physicians is extremely unsatisfactory from this point of view.

This is a view which I think is receiving increasing support, but there are great problems financially in respect of training in different settings.

One aspect of community training is, of course, to gain experience in extramural situations, and in this trainees are very much dependent on the practices of their trainers. 
Basically, it is difficult for trainees to be quite different in orientation and practice from their consultants.

Dr Paul Williams gave me preliminary figures from his survey of the extent to which consultant psychiatrists are engaged in GP attachment schemes. Out of 811 consultants, 19 per cent said that they or their junior staff spent some time in a GP setting, while 13 per cent said that they or their juniors spent some time in a mental health centre, that is, one to which the public have direct access, and usually away from NHS premises. Consultants at mental hospitals were rather more likely to be involved in this work than those in DGH units. It is clear from these figures that extramural work of this kind is still a minority activity amongst consultants, and this situation represents a problem for trainees.

The Richmond Fellowship report says some fundamental things about training for community mental health services-firstly, about the importance of apprenticeship as against academic knowledge. The old apprenticeship of mental hospitals is rightly discredited, but it is only from experience within a well functioning community-based service, with the guidance of experienced supervisors, that trainees can really learn how the system works. It is also in this setting that their personal qualities can best be assesed. 'Unless this experience is acquired in the right kind of apprenticeship, there is a serious risk that each type of professional will formulate the problems of the mentally ill merely in terms of his or her own particular techniques, will undervalue the skills of other professionals, and avoid altogether the range of "mundane" needs to which patients and relatives give high priority.' Therefore, it is suggested that there should be accreditation of overall community services for training, and that this should be for all disciplines working in them.

In academic training, common elements of the courses for the different professions could be brought together, so that some were held in common. Both academic and apprenticeship teaching should emphasize the principles of comprehensive community care in relation to the local characteristics of any catchment population. This would not only apply to psychiatrists, clinical psychologists, social workers and psychiatric nurses, but also to community physicians and GPs; some of the damage that has been done in social work by genericism might then be overcome. It is not possible for psychiatrists to be community-orientated without the co-operation of competent colleagues in other professions-at present, these are often absent.

I have two main reservations about these proposals, although I would support them in general. Firstly, there are very few district services deserving an ' $A$ ' from this point of view, and if training is over-concentrated, people living elsewhere may be worse off than ever. How will the medical work be done there? This is already emerging as a problem in connection with the College's accreditation exercise, and with plans by the DHSS to reduce numbers of trainees. Secondly, the different professions represent varying levels of academic attainment, not to mention differences in working conditions, professional structure, etc. Medicine is basically a non-hierarchical profession, whereas nursing and social work are rigidly hierarchical. Dr Douglas Bennett said some years ago that you cannot have blurring of roles without eventually having blurring of salaries. These difficulties should not be ignored-and above all, there is the question of the Membership Examination-would it have to be completely reformulated to account for a change of this kind?

The College's Working Party on Rehabilitation suggested that one consultant in each district should have special responsibility for the handicapped, both inside and outside hospital, which would include a special role in relation to planning, management and training of the service. In fact, the posts designated with an interest in rehabilitation have not been like this at all, but have been largely focused on the needs of long-stay in-patients.

The Working Party which I chaired was opposed to the principle of setting up a sub-specialty of community psychiatry, quite apart from the practical problems that would be involved in that. National policy requires that all psychiatrists practice on the basis of responsibility to the needs of defined communities. At the same time, we felt that innovation and experiment should be encouraged to provide models of good practice; these have nearly always stemmed from individual clinicians, who had the charisma and determination to establish them, which is one of the greatest potential assets of the medical role. It also seems significant that creative innovation seems to flourish more away from teaching centres, perhaps because clinicians there get used to making bricks without straw. Also, non-teaching hospitals seemed to be doing relatively better with this aspect of training - the same phenomenon as occurred in the development of general hospital psychiatry.

In the book Psychiatrists on Psychiatry, ${ }^{6}$ Jablensky deplores the poor teaching of epidemiology and social medicine in postgraduate psychiatric training, which he relates to the resistance of psychiatrists to learn from general public health experience. This is an important observation because national policy for mental health services is founded on responsibility for defined populations. The insights of epidemiology and social medicine are therefore essential to psychiatric training. Here, one should make more than a routine obeisance to the need for better research in the area of social and community psychiatry because better training depends very much on it.

I would strongly resist any movement towards the evolution of a 'Mental Health Professional', rather than a psychiatrist, nurse or social worker-this would be a loss of all the benefits of a profession's heritage for very vague potential benefits. My observations of this phenomenon in America suggest that it is extremely difficult to know what is going on between these people and patients or clients, and that the maintenance of standards becomes almost impossible.

My Working Party urged the JCHPT and College Assessors to insist on better social and community experience, particularly at senior registrar level, notwithstanding the demands of in-patient work. That is probably the best 
line to pursue now, but I hope that the other issues raised here will continue to receive attention. For the present, one must regretfully conclude that adequate training in community psychiatry has hardly begun.

\section{ACKNOWLEDGEMENTS}

My enquiries on this subject were answered with the utmost helpfulness by Drs David Fisher, Donald Dick, Peter Brook, Alexis Brook, Leonard Fagin, Douglas Brough, Christopher Fleming, Ross Mitchell, Julie Hollyman, Paul Williams, S. Kumar, and Robin Murray and Professors Sydney Brandon and John Wing.

\section{REFERENCES}

'Richmond Fellowship (1983) Mental Health and the Community London: Richmond Fellowship Press.
${ }^{2}$ Brook, C. P. B. (1974) The postgraduate education and training of consultant psychiatrists. British Journal of Psychiatry, 124, 109-24.

1__ (1981) Postgraduate psychiatric training. Medical Education, 15, 335-39.

${ }^{4}$ Royal College of Psychiatrists (1982) Should community psychiatrists be specialists? A report on specialist status from the Working Party of the Social and Community Psychiatry Section. Bulletin of the Royal College of Pșychiatrists, 6, 190-94.

'DALly, P. (1982) Community psychiatry (Correspondence). Bulletin of the Roval College of Psychiatrists, 6, 66.

'Jablensky, A. (1982) Chapter in Psychiatrists on Psychiatry (ed. M. Shepherd). Cambridge University Press.

(See also correspondence from Dr Seidel, pages 35-36.)

\title{
UK Workshop on Organization and Management of Psychiatric Services
}

\author{
A. V. P. Mackay, Physician Superintendent, Argyll; and Bute Hospital, Lochgilphead, Argyll and \\ Peter Kennedy, Consultant Psychiatrist, Bootham Park Hospital, York
}

Stimulated by the First International Conference on Organization and Management of Psychiatric Services in Montreal in Spring 1983, an idea arose which was translated into the first UK Workshop on Psychiatric Service Management held from 17 to 20 July 1984 in York. The theme was economics, addressed by a talented group of British health economists. The meeting was structured into a series of presentations followed by group discussion, culminating in group exercises involving informed criticism of selected research papers on economic appraisals of psychiatric services. Seminar topics included: What do we mean by efficiency in the delivery of psychiatric care? (Professor Alan Williams); What are the costs of delivering psychiatric care? (Ron Akehurst); Switching resources (Professor Alan Maynard); Measuring outcomes of health (Professor Alan Williams); Choosing options with a limited budget (Mike Drummond and Ron Akehurst). A special evening discussion was led by Tim Nodder (Deputy Secretary at the Department of Health and Social Security) who gave an eloquent account of Health Service Strategy vis- $\dot{a}$ vis mental health over a thirty-year historical perspective.

Eighteen delegates* attended the conference; consultant psychiatrists and community physicians from the four corners of the UK. Initial reaction was generally one of anomie in the face of novel concepts and alien terms-a striking, if predictable, demonstration of poverty of formal planning skills possessed by senior clinicians. But this was rapidly replaced by appreciation and admiration for our teachers who systematically and painlessly led the party through the jargon-ridden world of option appraisal, marginal analysis, cost-benefit analysis and efficiency. In everyday terms, it reduces to the skills of informed decision-making, skills which are becoming increasingly desirable for clinicians who wish to earn a position of participation in the shaping of the service in which they work. Economic appraisal ceased to be felt as some bête noire, some threat to humane priorities of patient welfare, being seen instead as a crucial ingredient in wise planning. An essential point which was embodied in the aims of the meeting is that ignorance breeds suspicion of the economic dimension in psychiatric service planning and, further, that absence of a basic level of such skills leaves the clinician pathetically vulnerable to manipulation by his administrative 'advisers'.

This brief conference gave cause for hope; your nonmedical colleagues who would baffle you or exclude you are probably only a seminar or two ahead. Even if clinicians fail to acquire sufficient facility with economic techniques to lead a planning group, they can, indeed should, acquire the minimum level necessary with which to perceive the difference between sense and nonsense in the information they are given.

\footnotetext{
*The names of participants are listed here so that any interested members may contact a local colleague for further details about the Workshops: David Bainton (Bristol and Weston Health Authority, Greyfriars, Bristol); Brian Barraclough (Royal South Hants Hospital, Southampton); Richard Cundall (St John's Hospital, Stone, Aylesbury); Robert Davidson (Gartloch Hospital, Glasgow); Hugh Freeman (Hope Hospital, Salford, Manchester): Iain Glen (Craig Dunain Hospital, Inverness); Madge Kaczmarczuk (Castleford and Mormanton Hospital, Castleford. W. Yorks.); Peter Kennedy (Bootham Park Hospital, York); John Loudon (Royal Edinburgh Hospital, Edinburgh); Angus Mackay (Argyll and Bute Hospital, Lochgilphead); Robin Philpott (Royal Liverpool Hospital, Liverpool); Edward Renvoize (Bootham Park Hospital, York); Anthony Rugg (Clifton Hospital, York); Oliver Russell (4I St Michael's Hill, Bristol); Alan Stephens (St George's Hospital, Morpeth); David Tait (Murray Royal Hospital, Perth); Hugh Warren (Naburn Hospital, York); Bill Wintersgill (York Health Authority, York).
} 